\title{
Study of flocculating effects of ozone on wastewater of woodworking enterprises
}

\author{
A.K. Mazitova (D, I.A. Sukhareva* (D), G.M. Sidorov, L.K. Abdrakhmanova, E.V. Kuznetsova \\ Ufa State Petroleum Technological University, Ufa, Bashkortostan Republic, Russia \\ * Corresponding author: e-mail: suxareva-ira@yandex.ru
}

\begin{abstract}
The sewer of woodworking enterprises in the construction industry are characterized by a high content of suspended and dissolved toxic substances, including phenol, and a high value of chemical oxygen consumption (COD). At the same time, some enterprises do not have their own local treatment facilities and need to develop their own integrated treatment systems. One of the effective methods for removing pollution is wastewater ozonation, used in three versions: flocculation with small doses of ozone (pre-ozonation) at the initial stage to remove suspended substances, oxidative ozonation and decontamination. However, methods for treating wastewater from wood processing plants using ozone have not been sufficiently studied. Therefore, we investigated the flocculating effect of ozone in the process of cleaning the effluents of the plywood-plate mill, tested the effect of the dose of ozone during flocculation in the presence of a small number of coagulants VPK-402 and Kaustamine-15 on the concentration of suspended substances, phenol and COD value. VPK-402 and Kaustamine-15 - reagents of regional production, are low-toxic and are allowed for use in the treatment of even drinking water. The results of the experiments on the pre-ozonation of wastewater showed a high efficiency of this method, which allows reducing COD by 3.8 (VPK-402) and 2.3 times (Kaustamine-15), phenol content by 2.9 (VPK-402) and 1.9 times (Kaustamine-15), suspended content by 4.0 (BПK-402) and 3.5 times (Kaustamine-15). The use of pre-ozonation makes it possible to completely abandon flocculants in the physicochemical stage of wastewater treatment. Coagulation-flocculation can be successfully carried out with ozone and coagulant in small doses of 2-5 and 40 mg/dm ${ }^{3}$ (VPK-402) or $50 \mathrm{mg} / \mathrm{dm}^{3}$ (Kaustamine-15), respectively, for 5 minutes. Physicochemical indicators of water quality improved compared to treatment with coagulant alone: COD decreased by $23 \%$, phenol content by $55 \%$, suspended substances by $22 \%$. The use of ozone as a flocculant in the clarification of wastewater reduces the cost of reagents, prevents secondary contamination of water, and increases the efficiency of further oxidative treatment.
\end{abstract}

KEYWORDS: coagulant, flocculant, ozonation, wastewater from woodworking enterprises.

FOR CITATION: Mazitova A.K., Sukhareva I.A., Sidorov G.M., Abdrakhmanova L.K.,Kuznetsova E.V. Study of flocculating effects of ozone on wastewater of woodworking enterprises. Nanotechnologies in Construction. 2020;12(4): 204-210. Available from: doi:10.15828/2075-8545-2020-12-4-204-210.

\section{INTRODUCTION}

$\mathrm{T}$ he production of wood chip materials is accompanied by pollution of wastewater with a large amount of suspended and dissolved toxic substances, including phenol, leading to a significant increase in the indicator of chemical oxygen consumption (COD), chromaticity and turbidity. At the same time, some enterprises do not have their own local treatment facilities and need to develop their own integrated treatment systems. At the initial stage of the technological scheme for the purification of such effluents, the necessary process is the precipitation of dissolved and suspended substances. We have previously investigated this purification method using various coagulants and flocculants [1-3]. The efficiency and economy of the processes of coagulation treatment of wastewater are determined by the stability of the dispersion system, which depends on a number of factors: the degree of dispersion, the nature of the surface of the particles, the value of the electrokinetic potential, the chemical nature of impurities (the presence of electrolytes, high molecular weight substances), the concentration of impurities, etc. In practice, water treatment uses different coagulants [4-7]. The most widespread compounds were aluminum, iron, magnesium and calcium. A feature of the coagulation treatment of waste water is the need to use coagulants that do not cause secondary water contamination. We have selected the most effective

๔ Mazitova A.K., Sukhareva I.A., Sidorov G.M., Abdrakhmanova L.K., Kuznetsova E.V., 2020 
coagulants and flocculants and their optimal doses for treatment of waste water of plywood-plate mills. Solutions of aluminum sulfate, iron (III) chloride, iron (II) sulfate and aluminum oxychloride $(\mathrm{AlOCl})$ were tested as coagulants and their optimal doses were determined: $\mathrm{Al}_{2}\left(\mathrm{SO}_{4}\right)_{3}-268 \mathrm{mg} / \mathrm{dm}^{3}, \mathrm{FeCl}_{3}-80 \mathrm{mg} / \mathrm{dm}^{3}, \mathrm{FeSO}_{4}-$ $180 \mathrm{mg} / \mathrm{dm}^{3}, \mathrm{AlOCl}-165 \mathrm{mg} / \mathrm{dm}^{3}$. To maximize the recovery of contaminants, the coagulation process was carried out in a range of optimal $\mathrm{pH}$ values that are directly related to the $\mathrm{pH}$ of the existence of the corresponding coagulant hydroxides. The greatest effect of wastewater treatment when used as a coagulant based on aluminum salts is achieved in the range of medium $\mathrm{pH}$ values from 6.5 to 8; when using iron salts - in the range of $\mathrm{pH}$ values from 4.1 to 14.0 [8]. As flocculants, we tested $0.1 \%$ solution of polyacrylamide (PAA), $0.5 \%$ solution of activated silicic acid (ASC), and $0.1 \%$ solution of cationic polyacrylamide brand REF FC. Optimal doses of flocculants are: PAA $-45 \mathrm{mg} / \mathrm{dm}^{3}, \mathrm{ACC}-53 \mathrm{mg} / \mathrm{dm}^{3}$, REF FC $40 \mathrm{mg} / \mathrm{dm}^{3}$. The results of the comparative analysis of the effect of the nature of the coagulant and flocculant on the degree of wastewater treatment of the plywood-plate mill showed the best results with the combination of PAA and $\mathrm{AlOCl}\left(\mathrm{COD}\right.$ decreases to $2100 \mathrm{mgO} / \mathrm{dm}^{3}$ ), REF FC and $\mathrm{AlOCl}\left(\mathrm{COD}\right.$ decreases to $2110 \mathrm{mgO}_{2} / \mathrm{dm}^{3}$ ); when PAA and $\mathrm{Al}_{2}\left(\mathrm{SO}_{4}\right)_{3}, \mathrm{REF} \mathrm{FC}$ and $\mathrm{AlOCl}$ are combined, the formaldehyde content in water is reduced to $0.05 \mathrm{mg} / \mathrm{dm}^{3}$; using $\mathrm{AlOCl}$ coagulant in combination with REF FC flocculant reduces phenol concentration to $1.0 \mathrm{mg} / \mathrm{dm}^{3}$. As a result, the most effective coagulant is $\mathrm{AlOCl}$ in the presence of the flocculant REF FC: The phenol content decreased by 2.6 times, while COD decreased by 3.6 times.

It is known from the literature to use ozone at the initial stage of water treatment at a dose causing flocculating action (pre-ozonation) [3, 9-19]. The use of ozone as a flocculant avoids secondary contamination of wastewater with traditional reagents - precipitators by reducing their dose, or their complete withdrawal. However, methods for treating wastewater of wood processing enterprises of the construction industry using ozone have not been sufficiently studied. Therefore, we investigated the flocculating effect of ozone on plywood-plate mill drains in the presence of low-toxic coagulants in order to precipitate suspended substances, reduce COD and phenol content.Among the large number of foreign and domestic coagulants represented on the Russian market, the most attractive from an economic point of view are the products of domestic companies: VPK-402 and Kaustamin-15, produced by JSC «Bashkir Soda Company». It should be noted that these reagents are produced at the enterprise for a fairly long time and are in stable demand among consumers. Polyelectrolyte of watersoluble cationic type VPK-402, or polyDADMAC, is a high-molecular compound of linear-cyclic structure polydiallyldimethylammonium chloride [20]. Molecu- lar weight from $10^{4}$ to $10^{6}$, cationic charge is located on secondary chain [21]. VPK-402 is available in various versions: for the treatment of drinking and industrial water. VPK-402 is used as a coagulant and flocculant for intensification of waste water treatment processes in the oil refining, pulp and paper, coal and chemical industries, antibiotic solutions treatment in the medical industry, the consumers of this product are also water utility companies. The water-soluble cationic type polyelectrolyte Kaustamin-15, or poly ECHDMA, is a quaternary polyamine polymer based on epichlorohydrin and dimethylamine [22]. The relative molecular weight is from $10^{4}$ to $10^{6}$; resistant to chlorination, compatible when mixed with inorganic coagulants. Unlike other polyelectrolytes, the cationic charge is located on the main molecular chain, which creates a coagulating effect even in highly contaminated waters. It is used to purify drinking water in household water supply systems, to intensify the processes of precipitation of suspended particles, active sludge, during dehydration of municipal and industrial wastewater, to treat the waste water of coal processing plants, paint and oil refineries, to treat industrial wastewater from mineral contaminants, to treat paper and textiles, in processes of rubber coagulation. In this regard, we conducted a study of the efficiency of wastewater treatment of plywood-plate plant by ozonation in the presence of a small number of available low-toxic coagulants VPK-402 and Kaustamin-15, stable at any $\mathrm{pH}$.

\section{METHODS AND MATERIALS}

The composition of the initial investigated water is given in the previous article [23], the temperature of the water during experiments is $22-24^{\circ} \mathrm{C}$. To clarify the waste water of the plywood-plate plant, we tested aqueous solutions of coagulants: Kaustamin-15 and VPK-402. It was previously determined that the optimum concentration should be $1 \%$ by weight. To do this, eight measuring cylinders with a capacity of 0.5 liters were poured into the tested water to the mark. Then, a different amount of milliliters of $1 \%$ coagulant solution was added to the cylinders with a dose of $5,10,20,30,40,50,60,70 \mathrm{mg} / \mathrm{dm}^{3}$ (based on the preparation of various doses of the coagulant in the range covering the intended optimal dose). The contents in all cylinders were quickly mixed for 15 to $20 \mathrm{sec}-$ onds, then slowly for 3 to 5 minutes. Flake drop time was measured, from which the optimal coagulant dose was determined. For the production of ozone, an ozone generator OGVK-02K was used to ensure the introduction of an ozone-oxygen mixture into water and contact with impurities - a reactor with a volume of $1 \mathrm{dm}^{3}$; device for monitoring ozone concentration in water - photometer "Expert-003." The treated water containing the optimal dose of coagulant was supplied with ozone using a porous ceramic dispersant. Flocculation was carried out in a 
non-precise mode, in an exhaust cabinet. Ozone was administered at various doses (from 1.0 to $7.0 \mathrm{mg} / \mathrm{dm}^{3}$ ) with vigorous stirring of waste water for 5 minutes. The treated water reactor was then left alone, measuring the flake drop time by which optimal ozone doses were determined. The weight concentration of the suspended substances was measured by gravimetric method (PND F 14.1: 2:4. 254-09). The mass concentration of phenol was measured by a photometric method after steam distillation (PND F 14.1: 2.105-97). COD (chemical oxygen consumption) was determined by the titrimetric method (PND F 14.1: 2: 3.100-97).

\section{RESULTS AND DISCUSSION}

We have selected the most effective coagulant and its optimal dose for treatment of waste water of plywoodplate mill. Dependence of flake deposition time on coagulant dose is given in Fig. 1.

From the obtained data (Fig. 1), optimal doses of coagulants were determined: VPK-402 - $40 \mathrm{mg} / \mathrm{dm}^{3}$, Kaustamin- $15-50 \mathrm{mg} / \mathrm{dm}^{3}$. These coagulants, unlike the coagulants we have previously tested $\left(\mathrm{Al}_{2}\left(\mathrm{SO}_{4}\right)_{3}, \mathrm{FeCl}_{3}\right.$, $\mathrm{FeSO}_{4}$ and $\mathrm{AlOCl}$ ), are in fact more adsorbents, and at the same time adsorption of contaminants dissolved in

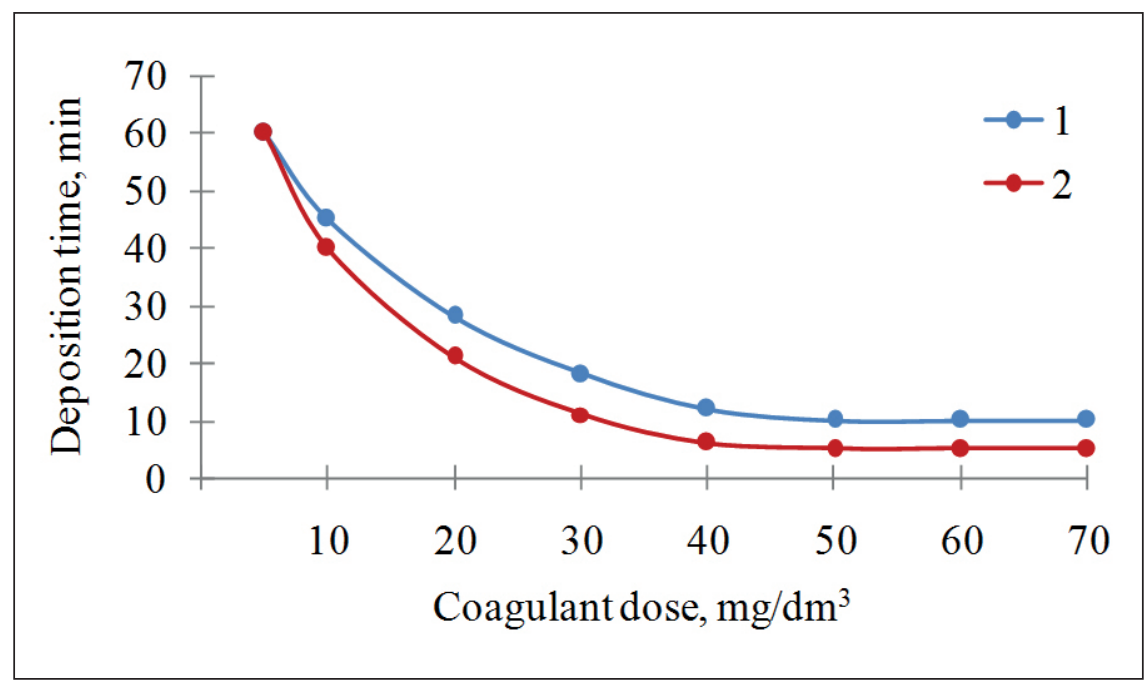

Fig. 1. Dependence of flake deposition time on coagulant dose:

1 - Kaustamin-15; 2 - VPK-402

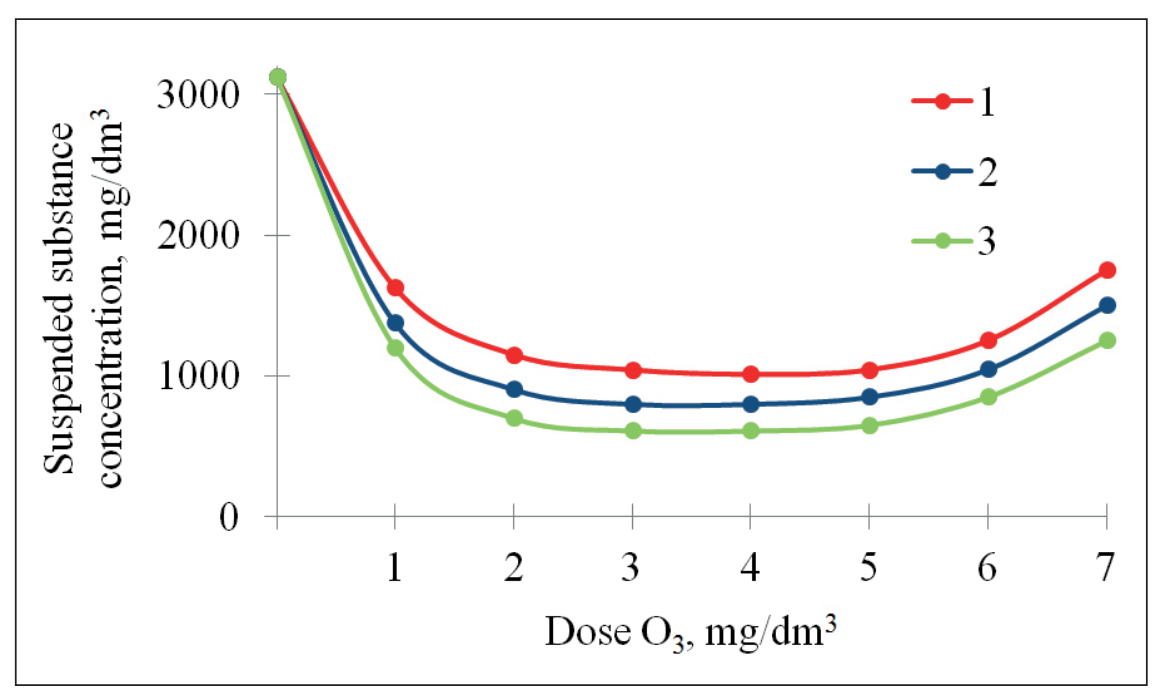

Fig. 2. Effect of ozone dose on the concentration of suspended substances

in waste water: 1 - without coagulant; 2 - in the presence of Kaustamin-15 coagulant; 3 - in the presence of VPK-402 coagulant 
water occurs on the surface of the suspension particles. Particles of the dispersed phase of the suspension are flocculation centers and simultaneously weighting agents, due to which the coagulation process accelerates and, as a result, the efficiency of treatment of waste water as a whole increases.

At the second stage of studies, water was treated together with ozone and coagulant. The results of tests of the flocculating effect of ozone in the presence of coagulants (Fig. 2) showed a decrease in the concentration of suspended substances by 3.5 times (Kaustamin-15) and 4 times (VPK-402) at a dose of ozone of $2-5 \mathrm{mg} / \mathrm{dm}^{3}$, which confirms the effect of flocculation. In the absence of a coagulant under the influence of ozone in the same dose, the concentration of suspended substances decreases by 3 times. Ozone as a flocculant disrupts the dynamic equilibrium in which impurities are in water, allows you to convert solutes into colloidal form, promotes the stratification of emulsions that were in a stable state under the influence of surfactants, and the precipitation of

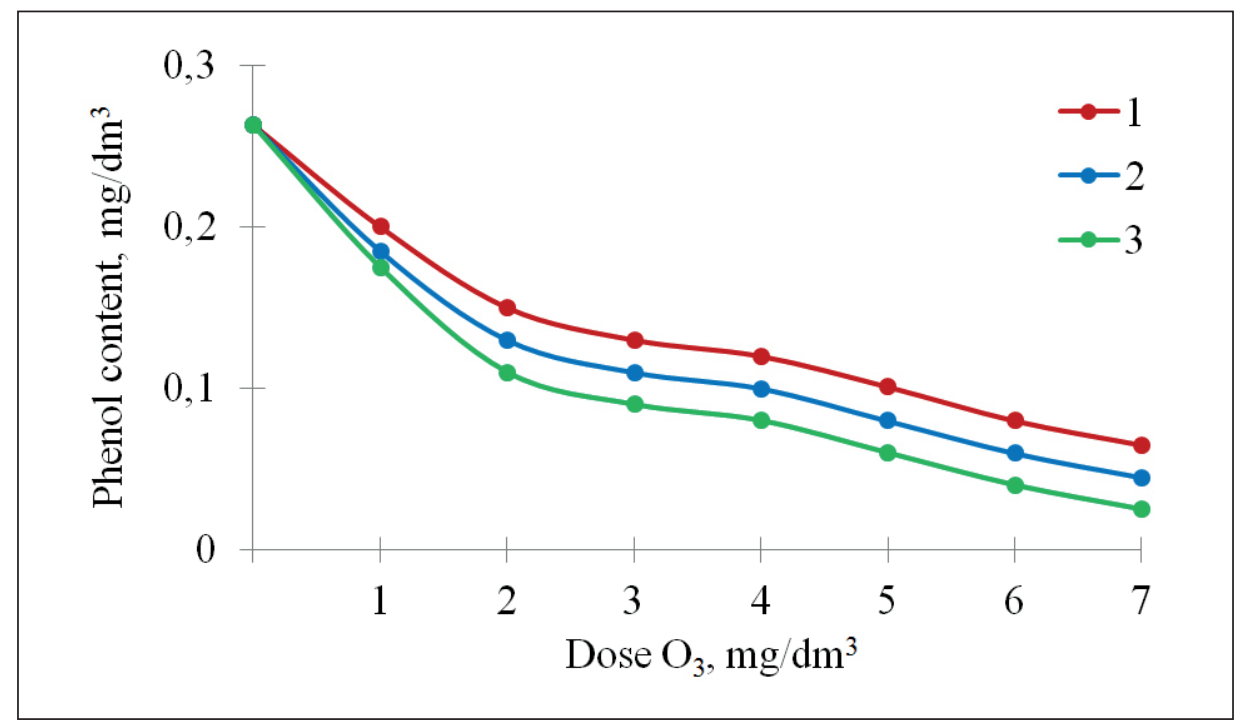

Fig. 3. Effect of ozone dose on phenol content in wastewater:

1 - without coagulant; 2 - in the presence of coagulant VPK-402;

3 - in the presence of Kaustamin-15 coagulant

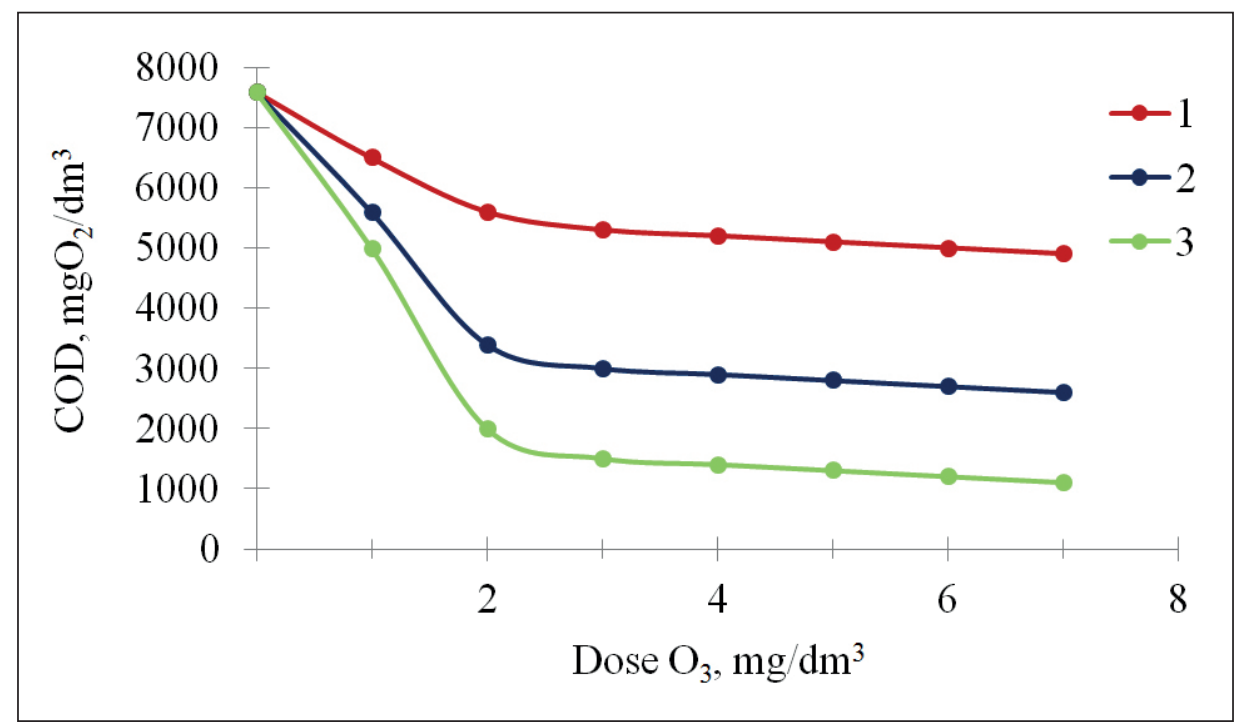

Fig. 4. Effect of ozone dose on change in COD value of wastewater:

1 - without coagulant; 2 - in the presence of coagulant VPK-402;

3 - in the presence of Kaustamin-15 coagulant 
Table

Results of a study on the effects of the nature of coagulant and the flocculating effect of ozone on the degree of purification

\begin{tabular}{|c|c|c|c|c|c|}
\hline Sample No. & Flocculant & Coagulant & $\mathrm{COD}, \mathrm{mgO}_{2} / \mathrm{dm}^{3}$ & $\begin{array}{l}\text { Phenols, } \\
10^{-1} \times \mathrm{mg} / \mathrm{dm}^{3}\end{array}$ & $\begin{array}{c}\text { Suspended } \\
\text { substances, } \mathrm{mg} / \mathrm{dm}^{3}\end{array}$ \\
\hline 1 & - & Kaustamin-15 & $4400 \pm 660$ & $2.50 \pm 0.38$ & $1090 \pm 59$ \\
\hline 2 & $\mathrm{O}_{3}$ & Kaustamin-15 & $3400 \pm 510$ & $1.40 \pm 0.21$ & $893 \pm 48$ \\
\hline 3 & - & VPK-402 & $2600 \pm 390$ & $2.00 \pm 0.30$ & $1000 \pm 54$ \\
\hline 4 & $\mathrm{O}_{3}$ & VPK-402 & $2000 \pm 314$ & $0.90 \pm 0.14$ & $782 \pm 42$ \\
\hline 5 & $\mathrm{O}_{3}$ & - & $5690 \pm 894$ & $1.50 \pm 0.23$ & $1042 \pm 56$ \\
\hline
\end{tabular}

impurities. As the ozone dose increases above $5 \mathrm{mg} / \mathrm{dm}^{3}$, the concentration of suspended substances begins to increase. This is probably due to the decomposition of large contamination macromolecules.

In subsequent runs, the effect of ozone dose on phenol content and COD value of wastewater was investigated (Fig. 3, 4). As the ozone dose increases from 1 to $7 \mathrm{mg} / \mathrm{dm}^{3}$, the phenol content decreases unevenly. Presumably, this is due to the adsorption of dissolved substances, including phenol, on precipitating flakes. At a dose of ozone above $5 \mathrm{mg} / \mathrm{dm}^{3}$, a more dramatic decrease in phenol content is observed due to an increase in the adsorption interface. In addition, the process of oxidizing pollutants under the influence of ozone is likely to begin.

From the results obtained (Fig. 4), it can be seen that a sharp decrease in COD is observed at a dose of ozone of $1-2 \mathrm{mg} / \mathrm{dm}^{3}$, and then a gradual decrease in the indicator occurs.

The results of the comparative analysis of the effect of the nature of the coagulant and the flocculating effect of ozone on the degree of wastewater treatment are shown in Table.

The best results are obtained with the combination of ozone and VPK-402, since the most effective treatment of waste water occurs: COD from 7600 to $2000 \mathrm{mO}_{2} / \mathrm{dm}^{3}$, phenol content from 0.263 to $0.090 \mathrm{mg} / \mathrm{dm}^{3}$, suspended substances from 3127 to $782.0 \mathrm{mg} / \mathrm{dm}^{3}$. There is probably a synergy between the flocculating effects of ozone and VPK-402.

Thus, the flocculating effect of ozone is most effective in the presence of coagulants VPK-402 and Kaustamin-15. The results of the experiments on the pre-ozonation of wastewater showed a high efficiency of this method, which allows reducing COD by 3.8 (VPK-402) and 2.3 times (Kaustamin-15), phenol content by 2.9 (VPK-402) and 1.9 times (Kaustamin-15), suspended content by 4.0 (VPK-402) and 3.5 times (Kaustamin-15).

\section{CONCLUSIONS}

These results make it clear that in order to improve the efficiency of wastewater treatment of the plywood-plate mill, it is necessary, after mechanical treatment at the initial stage, to conduct joint coagulation-flocculation with ozone and coagulant VPK-402 in small doses (2-5 and $40 \mathrm{mg} / \mathrm{dm}^{3}$, respectively) for 5 minutes. The investigated purification method allows to reduce flocculant costs, prevent secondary water contamination, increase efficiency of further oxidative purification.

\section{REFERENCES}

1. Aminova A.F., Sukhareva I.A., Martyasheva V.A., Baturina K.V. Issledovanie vliyaniya koagulyantov na ochistku stochnyh vod ufimskogo fanerno plitnogo kombinata. Oil and gas business. 2015; 13(3): 18-21.

2. Yagafarova G.G., Aminova A.F., Sukhareva I.A., Khangildina A.R., Khangildin R.I. Development of a method for treating wastewater from difficult-to-oxidize organic compounds. Water: chemistry and ecology. 2016; 1: 24-29. 
3. Mazitova A.K., Aminova A.F., Sukhareva I.A. Purification of wastewater of some construction materials production. In: IOP Conference Series: Materials Science and Engineering: international Conference on Construction, Architecture and Technosphere Safety, 25-27 September 2019. Vol. 687: ICCATS-2019.066073.

4. Zhukov A.I., Mongait I.D., Rodziller I.D. Process WasteWater Treatment Methods. Moscow: Stroyizdat; 1977.

5. YakovlevS.V., PeskovS.V., KarelinYa.A., LaskovYu.M., VoronovYu.V. Treatment of industrial wastewater. Moscow: Stroyizdat; 1985.

6. Rubinskaya A.V., Chistova N.G., AlashkevichYu.D. Efficiency of cooling water treatment in fiber boards production.Chemical technology of vegetable raw materials processing. 2008; 3: 354-358.

7. Chistova N.G., AlashkevichYu.D., Rubinskaya A.V. Problems of wastewater treatment in the production of wood fiber boards by wet method.In: Ecology and safety of life: Proceedings of the IV International Scientific and Practical Conference, 2004, Penza. 2004. P. 145-146.

8. Meshalkin A.V., Dmitrieva T.V., Strizhko L.S. Ecochemical Workshop: textbook. Moscow: Sayns-Press; 2002.

9. Kuzubova L.I., Kobrina V.N. Chemical methods of water treatment (chlorination, ozonation, fluorination). Novosibirsk: Ecology; 1996.

10. Mazitova A.K., Sukhareva I.A., Aminova G.K., Nasyrova G.M., Udalova E.A., Sergeev V.A. Study of the possibilities of using ozone as a flocculant. Bashkir Chemical Journal. 2019;26(4): 25-28.

11. Tskhe A.A., Khan V.A., Myshkin V.F., Kolesnikov V.P., Wilson E.V., PochuevYu.N., Lukanin A.A. Pre-ozonation - as a means of intensification of biological wastewater treatment processes. Scientific Journal of Kuban State Agrarian University. 2013;87:276-301.

12. Aminova A.F., Sukhareva I.A., Buylova E.A., Nezdyokin D.V., Fayzullina S.R. Wastewater treatment of wood processing industry using ozone. In: Problems of water, energy supply and ecology in modern construction: materials of the international scientific and technical conference. Baku: Azerbaijan University of Architecture and Construction; 2018.

13. Zhitenev B.N., Taratenkova M.A. Discoloration of surface waters by coagulation with preliminary ozonation for production water supply.Bulletin of Brest State Technical University. 2016;2: 67-70.

14. Ameta R. Advanced Oxidation Processes for Wastewater Treatment: Emerging Green Chemical Technology. Academic Press, 2018.

15. Himadri R.G. Advanced Oxidation Processes for the Treatment of Biorecalcitrant Organics in Wastewater. Critical reviews in environmental science and technology. 2014;44: 1167-1219.

16. Buyukada M. Modeling of decolorization of synthetic reactive dyestuff solutions with response surface methodology by a rapid and efficient process of ultrasound -assisted ozone oxidation. Desalination and water treatment. 2016;57: 14973-14985.

17. Hrishikesh V.K. Intensification of catalytic wet air oxidation for industrial effluent treatment using ozone and ultrasound as pretreatment.Desalination and water treatment. 2017; 58: 63-71.

18. Barry L.L.Forty Years of Advances in Ozone Technology.Ozone: Science\&Engineering. 2018; 40: 3-20.

19. KofmanV.Ya. New oxidizing technologies for water and wastewater treatment. Part 1. Water supply and sanitation. 2013;10: 68-78.

20. Asfandiyarova L.R., Godzhaeva A.R. Synthesis of water-soluble cationic polyelectrolyte based on epichlorohydrin and dimethylamine.The world of petroleum products. Oil Company Bulletin. 2013;12: 15-16.

21. Topchiev D.A., Malkanduev Yu.A. Kationnyepolielektrolity. Cationic polyelectrolytes. Gets, properties, and uses. Moscow: Academbook; 2004.

22. Daminev R.R, Fatkullin R.N. Asfandiyarov R.N., Asfandiyarova L.R., Yunusova G.V. Features of production of salt-free N, N-dimethyl-N, Ndiallylammonium chloride and polymer based on it.Butler messages. 2015; 43: 112-116.

23. Mazitova A.K., Sukhareva I.A., Aminova A.F., Yagafarova G.G., SavichevaYu.N. Ozonation of waste water of woodworking enterprises using a heterogeneous catalyst with nanopowders. Nanotechnology in Construction. 2019;11(4): 394-404. Available from: doi:10.15828/2075-8545-2019-11-4-394-404. 


\section{INFORMATION ABOUT THE AUTHORS}

Aliya K. Mazitova, Dr. Sci. (Chem.), Professor, Ufa State Petroleum Technological University; Ufa, Republic of Bashkortostan, Russia, ORCID: https://orcid.org/0000-0003-3853-4617, e-mail: elenaasf@yandex.ru

Irina A. Sukhareva, Cand. Sci. (Eng.), Associate Professor, Ufa State Petroleum Technological University; Ufa, Republic of Bashkortostan, Russia, ORCID: https://orcid.org/0000-0001-9669-7460, e-mail: suxareva-ira@yandex.ru

Georgy M. Sidorov, Dr. Sci. ( Eng.), Professor, Ufa State Petroleum Technological University; Ufa, Republic of Bashkortostan, Russia, e-mail: kaskad@ufanet.ru

Liliya K. Abdrakhmanova, Cand. Sci. (Eng.), Associate Professor, Ufa State Petroleum Technological University; Ufa, Republic of Bashkortostan, Russia, e-mail: liliya.abdrakhmanova.1955@gmail.com

Elena V. Kuznetsova, Cand. Sci. (Eng.), Associate Professor, Ufa State Petroleum Technological University; Ufa, Republic of Bashkortostan, Russia, e-mail:nsp-rb@mail.ru

\section{Authors declare the absence of any competing interests.}

Received: 06.07.2020.

Revised: 30.07.2020.

Accepted: 05.08.2020. 